\title{
Asymmetry and Persistence of Stock Returns: A Case of the Ghana Stock Exchange
}

\author{
Abonongo John ${ }^{1,}$, , Oduro F. T. ${ }^{1}$, Ackora-Prah J. ${ }^{1}$, Luguterah Albert ${ }^{2}$ \\ ${ }^{1}$ College of Science, Department of Mathematics, Kwame Nkrumah University of Science and Technology, Kumasi, Ghana \\ ${ }^{2}$ Faculty of Mathematical Sciences, Department of Statistics, University for Development Studies, Navrongo, Ghana
}

\section{Email address:}

abonongojohn@gmail.com (A. John)

${ }^{*}$ Corresponding author

\section{To cite this article:}

Abonongo John, Oduro F. T, Ackora-Prah J., Luguterah Albert. Asymmetry and Persistence of Stock Returns: A Case of the Ghana Stock Exchange. International Journal of Business and Economics Research. Vol. 5, No. 6, 2016, pp. 183-190. doi: 10.11648/j.ijber.20160506.11

Received: May 19, 2016; Accepted: May 31, 2016; Published: November 11, 2016

\begin{abstract}
Measuring and estimating volatility of asset return is bubbly for risk management, asset allocation, and option pricing. This paper investigated the asymmetry and persistence of the return of some stocks on the Ghana Stock Exchange using univariate TGARCH-M $(1,1)$ and half-life measure of the daily returns of eight stocks from 02/01/2004 to 20/12/2014. It was realized that, volatility was persistent (explosive process) in all the stocks. The persistence in volatility was extended in investigating the half-life measure of the stocks and it was realized that almost all the stocks had strong mean reversion and short half-life measure with the exception of Fan Milk Limited. Also all the returns series exhibited a positive leverage effect parameter indicating that bad news influenced volatility than good news of the same magnitude.
\end{abstract}

Keywords: Asymmetry, Persistent, Half-Life, Volatility, Leverage Effect

\section{Introduction}

Stock price volatility is an extremely important concept in finance for numerous reasons. The literature on stock price volatility agrees on one key phenomenon. There is evidence of several movements in stock prices. In other words, dynamic nature of stock price behaviour is an accepted phenomenon and all participants in stock markets including regulators, professionals and academics have consensus about it. But, what causes stock price volatility is a question that remains unsettled in finance field. This is because of the great number of complicated variables, which is not an easy task and up to now there is no consensus about it. However researchers in quest of answers to this question have investigated the stock price volatility from different angles. In this regards, from late twentieth century and particularly after introducing ARCH model by [8], as said by [3] and [27], a lot of studies accomplished in developed country and to some extent in developing countries has been done by researchers in this area using different methods.

[8] published a paper that measured the time-varying volatility. His model, ARCH, was based on the idea that a natural way to update a variance forecast is to average it with the most recent squared "surprise"(i.e. the squared deviation of the rate of return from its mean). While conventional time series and econometric models operate under an assumption of constant variance, the ARCH process allows the conditional variance to change over time as a function of past errors leaving the unconditional variance constant. [3] to overcome the ARCH limitations introduced his model, $\mathrm{ARCH}$ that generalized the ARCH model (GARCH) to allow for both a longer memory and a more flexible lag structure. As noted above, in the empirical application of the $\mathrm{ARCH}$ model, a relatively long lag in the conditional variance equation is often called for, and to avoid problems with negative variance parameters, a fixed lag structure is typically imposed. In the ARCH process the conditional variance is specified as a linear function of past sample variance only, whereas the GARCH process allows lagged conditional variances to enter in the model as well.

[9] introduced the ARCH-M model by extending the $\mathrm{ARCH}$ model to allow the conditional variance to be determinant of the mean. Whereas in its standard form, ARCH model expresses the conditional variance as a linear function of past squared innovations, in this new model they hypothesized that, 
changing conditional variance directly affect the expected return on a portfolio. Their results from applying this model to three different data sets of bond yields are quite promising. Consequently, they concluded that risk premia are not time invariant; rather they vary systematically with agent's perceptions of underlying uncertainty. [24] extended the $\mathrm{ARCH}$ framework in order to better describe the behaviour of return volatilities. Nelson's study was important because of the fact that it extended the ARCH methodology in a new direction, breaking the rigidness of the G/ARCH specification. The most important contribution was to propose a model (Exponential Autoregressive Conditional Heteroskedasticity $(\mathrm{EARCH}))$ to test the hypothesis that the variance of return was influenced differently by positive and negative excess returns. His study found that not only was the statement true, but also that excess returns were negatively related to stock market variance. [13] modified the primary restrictions of Generalized Autoregressive Conditional Heteroskedasticity- in Mean (GARCH-M) model based upon the truth that GARCH model enforce a symmetric response of volatility to positive and negative shocks, introduced the Glosten-JagannathanRunkle Generalized Autoregressive Conditional Heteroskedasticity (GJRGARCH) and the Threshold Generalized Autoregressive Conditional Heteroskedasticity (TGARCH) models. They concluded that there was a positive but significant relation between the conditional mean and conditional volatility of the excess return on stocks when the standard GARCH-M framework was used to model the stochastic volatility of stock returns.

[10] measured the impact of bad and good news on volatility and reported an asymmetry in stock market volatility towards good news as compared to bad news. More specifically, market volatility was assumed to be associated with the arrival of news. A sudden drop in price was associated with bad news on the other hand, a sudden increase in price was said to be due to good news. They found that bad news created more volatility than good news of equal importance. This asymmetric characteristic of market volatility has come to be known as the "leverage effect".

In stock market, negative shocks lead to higher volatility than positive shocks. In case of commodity and energy returns, asymmetry is observed in opposite direction. Energy return volatility reacts more to positive shocks than to negative shocks. For studying asymmetry in crude oil volatility, [23] used exponential GARCH model to evaluate varying effects of positive and negative shocks on oil return volatility. [5] also studied the asymmetry effect on two crude oil prices; West Texas Intermediaries (WTI) and Brent crude oil. He found that volatility reacts more to negative shocks than to positive shocks. However, it was evident only for Brent crude not for WTI crude oil. The literature on asymmetry of energy prices is limited to crude oil prices. Persistence or long memory plays a crucial role in volatility forecasting and it has immense influence in risk management, derivative pricing and portfolio management. Persistence implies that any shocks to volatility do not die quickly rather its effect endures. Among the studies, [17],
[26], [29] and [30] examined persistence in oil return volatility. [26] estimated volatility persistence of crude oil and natural gas using GARCH and 'half-life' volatility measure and found the evidence of persistence in the volatility of crude oil and natural gas. However, his measure of persistence suggested that the fluctuations were short-lived than previously assumed. If there was a shock to crude oil or natural gas prices, it lasted up to 5 to 10 weeks.

[1], estimated the daily returns of the Khartoum Stock Exchange using GARCH models. Their study showed that the conditional variance process was highly persistent and provided evidence on the existence of risk premium for the KSE index returns series. They also realised that, the asymmetric models provided better fit than the symmetric models which confirmed the existence of leverage effect. [28] also estimated persistence in crude oil and found the evidence of long memory even with structural break.

Also, [14] estimated and compared the asymmetry and persistence of volatility of crude oil, natural gas and coal. Their research revealed that, coal volatility exhibited strong mean reversion whereas crude oil and natural gas return volatility endured shocks for relatively higher periods. And that volatility of crude oil and gas increased after positive shocks in price.

[18] used Iterated Cumulative Sum of Squares (ICSS) to determine regime shifts and then applied in the asymmetric volatility models to study the impact of shocks on volatility persistence and asymmetry. Their results revealed that, the persistence and asymmetry in volatility were reduced considerably when regime shifts were taken into account in the models. [16] study in Nigeria obtained an evident of volatility clustering and volatility persistence and also asymmetric volatility effect in Nigeria.

Moreover, [25] examined the behaviour of stock return volatility in the Kenyan stock exchange phases for the NSE20 share index and the 10 sample stocks over 11 years. They employed the FIEGARCH $(1, \mathrm{~d}, 1)$ in fitting the asymmetry effect and volatility persistent. Their results revealed persistent bullish phases than bearish with bear phases much frequent. Also, there was non-systematic pattern across all the stocks though a higher degree dependence in both the level and volatility in the bull periods and that, the FIEGARCH models was capable of modelling volatility clustering and asymmetry in volatility.

The purpose of this paper is to investigate the asymmetry and persistence of some stocks on the Ghana Stock Exchange. This is to provide investors with information on how persistence some stocks are and their respective half-life measure so as make the right investment decisions.

\section{Materials and Methods of Analysis}

\subsection{Source of Data}

This paper used secondary data of 8 stocks (CAL Bank Limited, Produce Buying Company, Fan Milk Limited, Clydestone (Ghana) Limited, Enterprise Group Limited, 
Uniliver Ghana Limited, Tullow Oil Plc and Benso Oil Palm Plantation) from the Ghana Stock Exchange (GSE) and Annual Report Ghana databases comprising the daily closing prices from the period $02 / 01 / 2004$ to $20 / 12 / 2014$, totaling 7616 observations.

\subsection{Methods of Data Analysis}

The daily closing prices were converted into compound returns given by;

$$
X_{t}=\log \left(\frac{p_{t}}{p_{t-1}}\right)
$$

where $X_{t}$ is the continuous compound returns at time $t, p_{t}$ is the current closing stock price index at time $t$ and $p_{t-1}$ is the previous closing stock price index.

\subsection{Tests}

\subsubsection{Stationarity Test}

It is very paramount to establish the existence or nonexistence of unit root in the time series under study so as to be able to ascertain the nature of the process that produces the time series. This paper employed two quantitative unit root tests namely; the PhillipPerron (PP) unit root test and the Kwiatkowsky, Phillips, Schmidt and Shin (KPSS) test. The KPSS test was used to test the null hypothesis that the data generating process is stationary, $H_{o}: I(0)$ against the alternative that it is non-stationary, $H_{1}: I(1)$. This test was developed [19]. It assumes that there is no linear trend term and is given by;

$$
Y_{t}=X_{t}+Z_{t}, Z_{t} I(0)
$$

where $X_{t}$ is a random walk, $X_{t}=X_{t-1}+v_{t} ; v_{t} \sim N\left(0, \sigma_{v}^{2}\right)$ and $Z_{t}$ is a white noise series. The previous pair of hypothesis is equivalent to;

$$
\begin{aligned}
& H_{o}: \sigma_{v}^{2}=0 \\
& H_{1}: \sigma_{v}^{2}>0
\end{aligned}
$$

If $H_{o}$ is true, the model becomes $Y_{t}=$ constant + $Z_{t} ; Z_{t} I(0)$ hence $Y_{t}$ is stationary. The test statistic is given by;

$$
K P S S=\frac{1}{T^{2}} \sum_{t=1}^{T} \frac{s_{t}^{2}}{\widehat{\sigma}_{\infty}^{2}}
$$

where $T$ is the number of observations, $\hat{\sigma}_{\infty}^{2}$ is an estimator of the long-run variance of the process $Z_{t}$.

The PP statistic test the hypothesis;

$H_{o}$ : unit root against

$H_{1}$ : stationary about deterministic trend

Under the $H_{o}$ of $p=0$, the PP test $Z_{p}$ and $Z_{\tau}$ statistics have the same asymptotic distributions as the ADF t-statistic and normalized bias statistics. The PP test is categorized into two statistics known as Phillips $Z_{p}$ and $Z_{\tau}$ tests given by;

$$
Z_{p}=n\left(\hat{p}_{n}-1\right)-\frac{1}{2} \frac{n^{2} \widehat{\sigma}^{2}}{s_{n}^{2}}\left(\hat{\lambda}_{n}^{2}-\hat{\gamma}_{0, n}\right)
$$

$$
Z_{\tau}=\sqrt{\frac{\hat{\gamma}_{0, n}}{\widehat{\lambda}_{n}^{2}}} \cdot \frac{\hat{p}_{n}-1}{\widehat{\sigma}}-\frac{1}{2}\left(\hat{\lambda}_{n}^{2}-\hat{\gamma}_{0, n}\right) \frac{1}{\bar{\lambda}} \cdot \frac{n \widehat{\sigma}}{s_{n}}
$$

$\hat{\gamma}_{j, n}=\frac{1}{n} \sum_{i=j+1}^{n} \widehat{\varepsilon}_{l} \cdot \hat{\varepsilon}_{i-j}$, for $j=0$, then $\hat{\gamma}_{j, n}$ is a maximum likelihood estimate of the error terms whiles $\hat{\gamma}_{j, n}$ is the covariance between the error terms $j$-periods apart for $j>0$.

$\hat{\lambda}_{n}^{2}=\hat{\gamma}_{0, n}+2 \sum_{j=1}^{q}\left(1-\frac{j}{q+1}\right) \hat{\gamma}_{j, n}$, when there exist no autocorrelation between the error terms, $\hat{\gamma}_{j, n}=0$ for $j>0$, then $\hat{\lambda}^{2}{ }_{n}=\hat{\gamma}_{0, n}$.

\subsubsection{Jarque-Bera Test}

[15] is a goodness-of-fit test which examines if the sample data have kurtosis and skewness similar to a normal distribution.

The test statistic is given by;

$$
J B=T \cdot\left[\frac{S^{2}}{6}+\frac{(K-3)^{2}}{24}\right]
$$

where $S$ and $K$ are the sample skewness and kurtosis respectively.

The Hypothesis is given by;

$H_{o}$ : normality

$H_{1}$ : non-normality

If the sample data comes from a normal distribution JB should, asymptotically, have a chi-squared distribution with two degree of freedom.

\subsubsection{Univariate Ljung-Box Test}

The [21] was employed to test whether there exist autocorrelation $r_{l}$ in the returns series. It is of the assumption that, the returns series and standardized residuals contain no serial correlation up to a given lag $k$.

The statistic is given by;

$$
Q(K)=T(T+2) \sum_{l=1}^{k} \frac{r_{l}^{2}}{T-l}
$$

where $r_{l}$ is the residual sample autocorrelation at lag $l, \mathrm{~T}$ is the size of the series, $\mathrm{k}$ is the number of time lags included in the test. $Q(K)$ has an approximately chi-square distribution with $\mathrm{k}$ degree of freedom. The null hypothesis is rejected and concluded at $\alpha$-level of significance that, the residuals are free from serial correlation when the $p$-value is greater than the significance level.

\subsubsection{Testing for ARCH Effects}

In fitting GARCH models, it is very essential to examine the residuals for evidence of ARCH effects. The observation that the magnitude of current residuals for any financial time series tends to be non-linearly related to the magnitude of their past residuals form the reasoning for ARCH test. This paper employed the ARCH-LM test as it is the most widely used method to test for ARCH effects in empirical studies ([6] and [22]).

By representing the $i$ lag autocorrelation of the squared or absolute returns by $\widehat{p}_{\imath}$, the Ljung-Box statistic is given by;

$$
Q=T(T+2) \sum_{i=1}^{m} \frac{\hat{p}_{i}^{2}}{T-i} \sim \chi^{2}(m)
$$


The LM hypothesis is given by;

$H_{o}: \alpha_{1}=\alpha_{2}=\cdots=\alpha_{i}=0$ (no ARCH effect) against

$H_{1}: \alpha_{1} \neq \alpha_{2} \neq \cdots \neq \alpha_{i} \neq 0$ (ARCH effect)

for at least $i=1,2, \ldots, q$

The statistic of the LM test is given by;

$$
L M=T \cdot R^{2} \sim \chi^{2}(q)
$$

where $q$ is the number of restrictions placed on the model, $\mathrm{T}$ is the total observations and $R^{2}$ forms the regression.

\subsubsection{The Durbin-Watson Test}

The [7] was employed to determine whether the error term in the mean equation follows an AR (1) process. The test requires the error term $\varepsilon_{t}$ to be distributed $\mathrm{N}\left(0, \sigma^{2}\right)$ for the statistic to have an exact distribution. The test statistic is given as;

$$
d=\frac{\sum_{i=2}^{n}\left(e_{i}-e_{i-1}\right)^{2}}{\sum_{i=1}^{n} e_{i}^{2}}
$$

where $e_{i}=y_{i}-\hat{y}_{i}$ and $y_{i}$ and $\hat{y}_{i}$ are the observed and predicted values of the response variable for individual $i$ respectively. $d$ becomes smaller as the serial correlations increases.

The hypothesis is given by;

$$
\begin{aligned}
& H_{o}: \rho=0 \\
& H_{1}: \rho>0
\end{aligned}
$$

Also, the $d$ statistic can take on values between 0 and 4 and under the null hypothesis $d$ is equal 2 .

\subsubsection{The Breusch-Godfrey Test}

This is also an LM test which was used to test for higherorder serial correlation in the disturbance.

The test statistic is given by;

$$
B-G=N R^{2}
$$

where $\mathrm{N}$ is the number of observations and $R^{2}$ is the simple $R^{2}$ from the regression

$$
\hat{u}_{t}=\gamma_{1} \hat{u}_{t-1}+\cdots+\gamma_{p} \hat{u}_{t-p}+\beta_{1} x_{1 t}+\cdots+\beta_{k} x_{k t}+\varepsilon_{t}
$$

The hypothesis is given by;

$$
\begin{gathered}
H_{o}: \text { no autocorrelation } \\
H_{1}: \text { autocorrelation }
\end{gathered}
$$

The test is asymptotically $\chi^{2}(\mathrm{p})$ distributed.

\subsection{The Mean Equation}

In modelling volatility, it is very essential to specify an appropriate mean equation. The mean equation should be white noise series, that is it should have a finite mean and variance; constant mean and variance, zero autocovariance, except at lag zero. Comparatively following [31] and [6], this paper employed the mean equation given by:

$$
X_{t}=\mu+\lambda X_{t-1}+\varepsilon_{t}
$$

where $X_{t}$ is the returns for each stock, $\mu$ is a constant, $\lambda$ is the coefficient of $X_{t-1}$ and $\varepsilon_{t}$ is the innovation.

\subsection{The Threshold GARCH-M (TGARCH-M)}

This model was proposed by [13] and [32]. It is simply a re-specification of the GARCH-M model with an additional term to account for asymmetry (leverage effect). In the general specification of this model, the TGARCH $(p, q)$ model is given by;

$$
\sigma_{t}^{2}=\alpha_{o}+\sum_{i=1}^{p}\left(\alpha_{i}+\gamma_{i} d_{t-i}\right) \varepsilon_{t-i}^{2}+\sum_{j=1}^{q} \beta_{j} \sigma_{t-j}^{2}
$$

where $\alpha_{o}$ is a constant, $d$ is the asymmetric component and $\gamma$ is the asymmetric coefficient. $\alpha_{i}, \gamma_{i}$ and $\beta_{j}$ are non-negative. Assuming the mean equation in Equation (13), the variance equation for TGARCH-M $(1,1)$ is given by;

$$
\begin{aligned}
& \sigma_{t}^{2}=\alpha_{o}+\alpha_{1} \varepsilon_{t-1}^{2}+\gamma_{1} d_{t-1} \varepsilon_{t-1}^{2}+\beta_{1} \sigma_{t-1}^{2}
\end{aligned}
$$

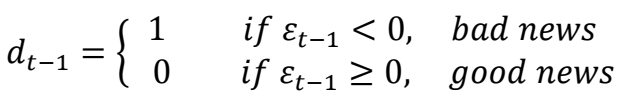

If $\gamma>0$, then leverage effects exist in stock markets and if $\gamma \neq 0$ then the impact of news is asymmetric [12]. Also when $\gamma=0$, the model collapses to the standard GARCH form. Nevertheless, when the shock is positive (good news), the volatility is $\alpha_{1}$, whereas if the news is negative (bad news), the effect on volatility is $\alpha_{1}+\gamma_{1}$. Similarly, if $\gamma$ is positive and statistically significant then negative shocks will have a larger effect on $\sigma_{t}^{2}$ than positive shocks [4]. Also, since the conditional variance must be positive, the constraints of the parameters are $\alpha_{o}>0, \alpha_{1} \geq 0, \beta_{1} \geq 0$ and $\alpha_{1}+\gamma_{1} \geq 0$. The model is stationary if $\gamma_{1}<2\left(1-\alpha_{1}-\beta_{1}\right)$.

\subsection{Student-t Distributional Assumption}

The student-t distributional assumption was employed to account for fat tails that are common in most financial data. The ARCH models were estimated using the maximum likelihood approach given a distributional assumption. The contribution to the likelihood for observation $t$ for the Student-t distribution is given by;

$$
l_{t}=-\frac{1}{2} \log \left(\frac{\pi(v-2) \Gamma\left(\frac{1}{2}\right)^{2}}{\Gamma\left(\frac{v+1}{2}\right)^{2}}\right)-\frac{1}{2} \log \sigma_{t}^{2}-\frac{v+1}{2} \log \left(1+\frac{\left(y_{t}-X^{\prime}{ }_{t} \theta\right)^{2}}{\sigma_{t}^{2}(v-2)}\right)
$$

where $\Gamma($.$) is the gamma function and v>2$ is a shape parameter which controls the tail behaviour. When $v \rightarrow \infty$ the distribution converges to Gaussian distribution.

\subsection{Mean Reversion}

Mean reversion implies that current information have no 
influence on the long run forecast of the volatility. Persistence dynamics in volatility is generally captured in the GARCH coefficient(s) of a stationary GARCH model. In stationary GARCH models, the volatility mean reverts to its long run level, at a rate given by the sum of $\mathrm{ARCH}$ and GARCH coefficients, which is usually close to one (1) for financial time series. The average number of time periods for the volatility to revert to its long run level is measured by the half-life of the volatility shock. The mean reverting form of the basic GARCH $(1,1)$ model is given by;

$$
\left(\varepsilon_{t}^{2}-\bar{\sigma}^{2}\right)=\left(\alpha_{1}+\beta_{1}\right)\left(\varepsilon_{t-1}^{2}-\bar{\sigma}^{2}\right)+X_{t}+\beta_{1} X_{t-1}
$$

where $\bar{\sigma}^{2}=\frac{\alpha_{o}}{1-\alpha_{1}-\beta_{1}}$, the unconditional long run level of volatility and $X_{t}=\left(\varepsilon_{t}^{2}-\bar{\sigma}^{2}\right)$. The magnitude of the mean reverting rate $\alpha_{1}+\beta_{1}$ controls the speed of the mean reversion.

\subsection{Half-Life}

One measure of volatility persistence is the volatility halflife $\tau$, [11] defined half-life as the time required for the volatility to move half way back towards its unconditional mean. More precisely, $\tau$ is the smallest $k$ such that

$$
\left|\sigma_{t+k \mid t}-\bar{\sigma}^{2}\right|=\frac{1}{2}\left|\sigma_{t+1 \mid t}-\bar{\sigma}^{2}\right|
$$

where $k$ is the number of days, $\sigma_{t+k \mid t}$ is the conditional expected value of volatility $k$ days into the future and $\bar{\sigma}^{2}$ is the unconditional long run level of volatility (the mean level to which the unconditional variance eventually reverts).

Also, the GARCH $(1,1)$ process is mean reverting if $\left(\alpha_{1}+\beta_{1}\right)<1$ since if this condition is satisfied, $\sigma_{t+k \mid t} \rightarrow \bar{\sigma}^{2}$ as $k \rightarrow \infty$. Thus, the forecast conditional variance reverts to the unconditional variance as the forecast horizon increases.

For $k \geq 2$ and a $\operatorname{GARCH}(1,1)$ process, the value of $\sigma_{t+k \mid t}$ is given by;

$$
\sigma_{t+k \mid t}=\bar{\sigma}^{2}+\left(\alpha_{1}+\beta_{1}\right)^{k-1}\left(\sigma_{t+1}-\bar{\sigma}^{2}\right), k \geq 2
$$

From Equation (19) and Equation (20), the number of days $k$ for a $\operatorname{GARCH}(1,1)$ process is given by;

$$
\left|\bar{\sigma}^{2}+\left(\alpha_{1}+\beta_{1}\right)^{k-1}\left(\sigma_{t+1}-\bar{\sigma}^{2}\right)-\bar{\sigma}^{2}\right|=\frac{1}{2}\left|\sigma_{t+1 \mid t}-\bar{\sigma}^{2}\right|(21)
$$

Therefore the half-life of a $\operatorname{GARCH}(1,1)$ process is given by;

$$
\tau=\frac{\left.\log \left[\left(\alpha_{1}+\beta_{1}\right)\right) / 2\right]}{\log \left(\alpha_{1}+\beta_{1}\right)}
$$

\section{Results and Discussion}

\subsection{Descriptive Statistics}

Table 1 shows the summary statistics of the returns series. Most of the stocks had positive mean returns (CAL Bnak Limited, Fan Milk Limited,Enterprise Group Limited, Uniliver Ghana Limited, Tullow Oil Plc and Benso Oil Palm Plantation) ranging from 0.0002 to 0.0020 . The rest of the stocks (Produce Buying Company and Clydestone (Ghana) Limited) had negative mean returns ranging from -0.0019 to 0.0002. The highest mean return was recorded in Benso Oil Palm Plantation (0.0020) and the lowest mean return recorded in Produce Buying Company (-0.0019). A positive mean return indicates that investors of such stocks made gains whereas those with negative mean return shows that investors made losses. The standard deviation as a measure of risk was high in Tullow Oil Plc (0.0527) and low in Uniliver Ghana Limited (0.0187) indicating the risk levels across the stocks. The variability between risk and return as a measure of coefficient of variation ranges from -24856.2300 (Clydestone (Ghana) Limited) to 16299.1900 (Enterprise Group Limited). Also, most of the mean returns were positively skewed ranging from 0.5900 to 28.7400 . This indicates that, the upper tail of the distribution of the return were ticker than the lower tail and that there were higher chances of gains than losses. That is, there was greater probability of making gains by investors in such stocks. Nevertheless, Enterprise Group Limited recorded a negative skewness (-16.8800) indicating that there was a high probability of making loss than gain by investors. The excess kurtosis ranged from 32.8200 to 866.0000 which are greater than 3. This means that the underlying distribution of the returns are leptokurtic (highly peaked) in nature and heavy tailed and that there was more frequently extremely large deviations from the mean returns than a Gaussian distribution and hence making the stocks highly volatile.

Table 1. Descriptive Statistics of the Returns Series.

\begin{tabular}{lllll}
\hline Stock & Mean & St. Dev & CV & Skewness \\
\hline CAL Bank Limited & 0.0013 & 0.0425 & 338.3000 & 4.6600 \\
Produce Buying Company & -0.0019 & 0.0223 & 2309.6400 & 1.9100 \\
Fan Milk Limited & 0.0012 & 0.0216 & 1800.6600 & 0.7200 \\
Clydestone (Ghana) Limited & -0.0002 & 0.0460 & -24856.2300 & 0.5900 \\
Enterprise Group Limited & 0.0002 & 0.0380 & 16299.1900 & -16.8800 \\
Uniliver Ghana Limited & 0.0009 & 0.0187 & 2031.5300 & 2.2300 \\
Tullow Oil Plc & 0.0017 & 0.0527 & 3058.0600 & 28.7400 \\
Benso Oil Palm Plantation & 0.0020 & 0.0420 & 2154.5100 & 32.8200 \\
\hline
\end{tabular}

\subsection{Further Analysis}

The PP and KPSS was employed in testing and confirming stationarity of the returns series. From Table 2, it is evident that for the PP tests, $p$-values were very significant at 5\% significance level and therefore the null hypothesis of non- 
stationary or unit root was rejected. In the case of the KPSS test, we failed to reject the null hypothesis of stationary since the test was significant at the $5 \%$ significance level.

Table 2. PP Test and KPSS Test of the Returns Series.

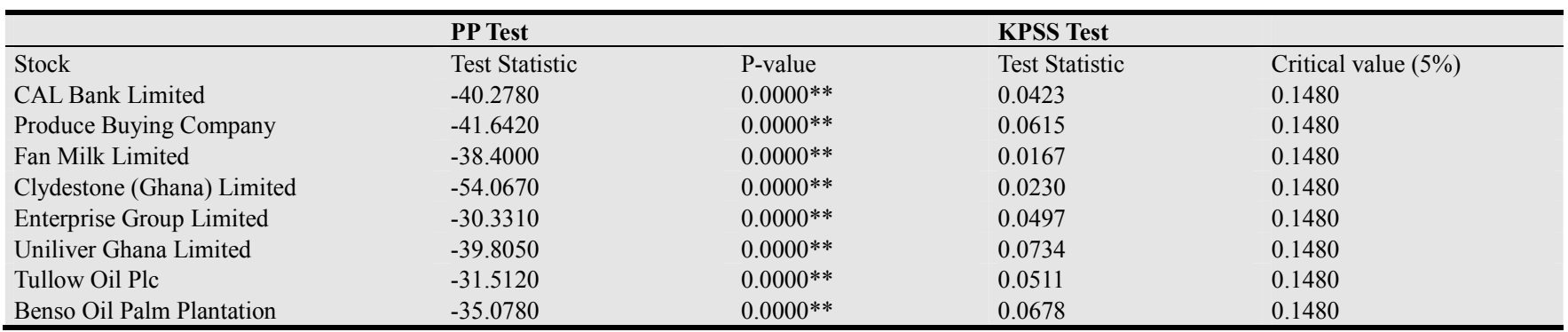

** Significant at 5\% significance level.

The residuals of the individual equations were examined for the presence or absence of conditional heteroskedasticity. The ARCH-LM test was conducted at lags 1, 7 and 14. It is evident from Table 3 that all the returns series exhibited ARCH effects at the 5\% significance level.

Table 3. ARCH-LM Test of the Selected Returns Series.

\begin{tabular}{|c|c|c|c|}
\hline Stock & Lag & Test Statistic & P-value \\
\hline \multirow{3}{*}{ CAL Bank Limited } & 1 & 125.1810 & $0.0000 * *$ \\
\hline & 7 & 148.5370 & $0.0000 * *$ \\
\hline & 14 & 186.9760 & $0.0000 * *$ \\
\hline \multirow{3}{*}{ Produce Buying Company } & 1 & 6.8591 & $0.0088 * *$ \\
\hline & 7 & 21.8946 & $0.0026 * *$ \\
\hline & 14 & 40.7375 & $0.0002 * *$ \\
\hline \multirow{3}{*}{ Fan Milk Limited } & 1 & 73.3761 & $0.0000 * *$ \\
\hline & 7 & 77.4349 & $0.0000 * *$ \\
\hline & 14 & 80.9421 & $0.0000 * *$ \\
\hline \multirow{3}{*}{ Clydestone (Ghana) Limited } & 1 & 130.3180 & $0.0000 * *$ \\
\hline & 7 & 133.4630 & $0.0000 * *$ \\
\hline & 14 & 138.8120 & $0.0000 * *$ \\
\hline \multirow{3}{*}{ Enterprise Group Limited } & 1 & 26.6978 & $0.0000 * *$ \\
\hline & 7 & 36.6906 & $0.0000 * *$ \\
\hline & 14 & 36.4258 & $0.0000 * *$ \\
\hline \multirow{3}{*}{ Uniliver Ghana Limited } & 1 & 59.7481 & $0.0000 * *$ \\
\hline & 7 & 61.2771 & $0.0000 * *$ \\
\hline & 14 & 60.9034 & $0.0000 * *$ \\
\hline \multirow{3}{*}{ Tullow Oil Plc } & 1 & 15.1319 & $0.0000 * *$ \\
\hline & 7 & 24.9135 & $0.0008 * *$ \\
\hline & 14 & 40.8408 & $0.0002 * *$ \\
\hline \multirow{3}{*}{ Benso Oil Palm Plantation } & 1 & 23.8970 & $0.0003 * *$ \\
\hline & 7 & 56.0000 & $0.0001 * *$ \\
\hline & 14 & 163.8830 & $0.0000 * *$ \\
\hline
\end{tabular}

** Significant at 5\% significance level

The returns series were tested for normality, autocorrelation and heteroskedasticity using the Jarque-Bera and Ljung Box tests respectively. It is evident from Table 4 that, the Jarque-Bera test for normality was significant at the $5 \%$ significance level, therefore we concluded that the returns series are not normally distributed. The $L B(14)$ and $L B^{2}(14)$ are all significant at the $5 \%$ level of significance. We therefore reject the null hypothesis of no autocorrelation in the levels of the returns series. The significance of $L B^{2}(14)$ statistic suggest the presence of ARCH effects and hence making an AR(1) conditional mean model more suitable for GARCH specification and it also indicates the presence of
Therefore, the returns series were all stationary at the 5\% level of significance. volatility clustering.

Table 4. Test for Normality, Autocorrelation and Heteroscedascitity of Return Series.

\begin{tabular}{llll}
\hline Stock & Jarque-Bera & $\boldsymbol{L B}(\mathbf{1 4})$ & $\boldsymbol{L B}^{\mathbf{2}}(\mathbf{1 4})$ \\
\hline CAL Bank Limited & $1.9098^{*}$ & $30.5740^{*}$ & $52.7909^{*}$ \\
Produce Buying Company & $42803.6000^{*}$ & $22.3281^{*}$ & $32.7670^{*}$ \\
Fan Milk Limited & $66302.5000^{*}$ & $51.9865^{*}$ & $38.6640^{*}$ \\
Clydestone (Ghana) Limited & $42308.9000^{*}$ & $68.4155^{*}$ & $42.4638^{*}$ \\
Enterprise Group Limited & $987916.0000^{*}$ & $33.8373^{*}$ & $56.0461^{*}$ \\
Uniliver Ghana Limited & $337264.0000^{*}$ & $58.9513^{*}$ & $46.8042^{*}$ \\
Tullow Oil Plc & $634210.0000^{*}$ & $34.5074^{*}$ & $49.7469^{*}$ \\
Benso Oil Palm Plantation & $1.5759^{*}$ & $38.7833^{*}$ & $32.8956^{*}$ \\
\hline
\end{tabular}

*Significant at 5\% significance level.

From Table 5, it is evident that the DW-AR(1) had indications of autocorrelation but the B-G AR(1) indicated no evidence of autocorrelation since it was not significant at the $5 \%$ level of significance across the entire returns series, therefore, we fail to reject the null hypothesis of no autocorrelation. Thus, making the choice of mean equation more appropriate for the GARCH estimation.

Table 5. Mean Equation Results for the Returns Series.

\begin{tabular}{llll}
\hline Stock & DW-AR(1) & B-G(1) & ARCHLM AR(1) \\
\hline CAL Bank Limited & 2.0300 & 0.0609 & $0.0000^{*}$ \\
Produce Buying Company & 1.9930 & 0.9129 & $0.0000^{*}$ \\
Fan Milk Limited & 1.9856 & 0.3787 & $0.0000^{*}$ \\
Clydestone (Ghana) limited & 2.1602 & 0.5620 & $0.0000^{*}$ \\
Enterprise Group Limited & 2.0019 & 0.9014 & $0.0000^{*}$ \\
Uniliver Ghana Limited & 1.9043 & 0.3965 & $0.0000^{*}$ \\
Tullow Oil Plc & 2.0043 & 0.5908 & $0.0000^{*}$ \\
Benso Oil Palm Plantation & 2.9043 & 0.2899 & $0.0000^{*}$ \\
\hline
\end{tabular}

*Significant at 5\% significance level.

The TGARCH was investigated for stationarity by summing the $\operatorname{ARCH}(\alpha)$ and $\operatorname{GARCH}(\beta)$ coefficients. As it was reported in Table 6 , all the estimated models were stationary indicating that the TGARCH was appropriate for asymmetric modelling of volatility. Again, the summation of the ARCH and GARCH coefficients was extended in measuring the level of persistence. It was evident that, the summation of $\alpha$ and $\beta$ were all closer to one (1) indicating their persistence levels. Fan Milk Limited exhibited the 
highest level of persistence (0.9622) with the least persistence (0.7580) level recorded in Produce Buying Company. Also, the TGARCH was extended in examining the leverage effect parameter $\gamma$, it was evident the leverage effect parameter across all the returns series were positive and significant at the 5\% significance level. This means that there was the probability of bad news influencing volatility than good news of the same magnitude hence making volatility across the stocks to be asymmetric in nature. All the models were tested for ARCH effects and it was clear that the ARCH-LM test was not significant at the 5\% level of significance hence there was no further ARCH effects.

Table 6. Estimated TGARCH-M (1,1) Model.

\begin{tabular}{llll}
\hline Stock & $\boldsymbol{\alpha}+\boldsymbol{\beta}$ & $\boldsymbol{\gamma}$ & ARCHLM \\
\hline CAL Bank Limited & 0.8712 & $0.0816^{*}$ & 0.6183 \\
Produce Buying Company & 0.7580 & $0.0974^{*}$ & 0.6103 \\
Fan Milk Limited & 0.9622 & $0.2940^{*}$ & 0.0925 \\
Clydestone (Ghana) Limited & 0.8275 & $0.0063^{*}$ & 0.8461 \\
Enterprise Group Limited & 0.8927 & $0.1546^{*}$ & 0.0572 \\
Uniliver Ghana Limited & 0.8149 & $0.4105^{*}$ & 0.5812 \\
Tullow Oil Plc & 0.8301 & $0.3827^{*}$ & 0.3086 \\
Benso Oil Palm Plantation & 0.7789 & $0.3030^{*}$ & 0.7154 \\
\hline
\end{tabular}

* Significant at $5 \%$ significance level.

The persistence and half-life measure of volatility of the returns series were investigated from the TGARCH-M $(1,1)$ model. The summation of $\alpha$ and $\beta$ was used and it is evident from Table 7 , all the 8 returns series were persistent exhibiting long-memory since their summation of $\alpha$ and $\beta$ were closer to one (1). Also, in terms of mean reversion, almost all the returns series have strong mean reversion with the exception of Fan Milk Limited. Fan Milk Limited exhibited the highest persistence level. The half-life measure of volatility also revealed the same trend. The half-life of most of returns series were short (CAL Bank Limited (6 days), Produce Buying Company (4 days), Clydeston (Ghana) Limited (5 days), Enterprise Group Limited (7 days), Uniliver Ghana Limited (4 days), Tullow Oil Limited (5 days) and Benso Oil Palm Plantation (4 days)) with the exception of Fan Milk Limited (19 days). It was also clear that, once the returns series were less persistent, their halflife measure of volatility tends to be short. The persistence and half-life in volatility showed that all the eight returns series exhibited some level of volatility persistence. This degree of persistence was extended in measuring the half-life in volatility. Stocks that exhibited high degree of persistence imply their volatility will not move quickly to their long-run volatility levels whereas those with less degree of persistence will have their volatility moving very quickly to their longrun volatility levels. That is, there is the expectation that stocks with high degree of persistence will have high half-life and weak mean reversion whereas those with low persistence will have low half-life and strong mean reversion. The implication of weak and strong mean reversion is that, for stocks with strong mean reversion means that, the returns of those stocks approaches their average volatility very quickly whereas for stocks with weak mean reversion, their returns takes a long period to return towards their average volatility. Therefore, the results showed that, Produce Buying Company, Uniliver Ghana Limited and Benso Oil Palm Plantation had strong mean reversion since they all had their half-life measure been four (4 days). This means that, any shock to any of these stocks take 4 days to return half-way back without any further volatility (i.e. a shock takes 4 days to return half-way back to its volatility). Also, CAL Bank Limited, Clydestone, Enterprise Group and Tullow Oil Plc have strong mean reversion since the half-life measure were 6 days, 5 days, 7 days and 5 days respectively. This implies that a shock to CAL Bank Limited will take 6 days to return half-way back to its volatility, a shock to Clydestone (Ghana) Limited will take 5 days to revert, any shock to Enterprise Group Limited and Tullow will take 7 days and 5 days respectively to return half-way back without any further volatility. The half-life measure of Fan Milk Limited was 19 days indicating that any shock to Fan Milk Limited will take 19 days to mean revert. This implies that, investors will prefer stocks that have strong mean reversion since their volatility does not stay for a long time. But in the situation where positive shocks increases volatility, investors will prefer to invest in stocks that have high persistence measure of volatility and weak mean reversion. Also in a market where risk is priced, investors will prefer investing in stocks with high half-life measure since at the end of the day their returns will match the risk taken.

Table 7. Persistence and Half-life Volatility measure of the Returns Series.

\begin{tabular}{lll}
\hline Stock & $\boldsymbol{\alpha}+\boldsymbol{\beta}$ & $\begin{array}{l}\text { Half-life volatility measure } \\
\text { (days) }\end{array}$ \\
\hline CAL Bank Limited & 0.8712 & 6 \\
Produce Buying Company & 0.7580 & 4 \\
Fan Milk Limited & 0.9622 & 19 \\
Clydestone (Ghana) Limited & 0.8275 & 5 \\
Enterprise Group Limited & 0.8927 & 7 \\
Uniliver Ghana Limited & 0.8149 & 4 \\
Tullow Oil Plc & 0.8301 & 5 \\
Benso Oil Palm Plantation & 0.7789 & 4 \\
\hline
\end{tabular}

\section{Conclusion}

This paper examined the asymmetry and persistence in stock returns using univariate TGARCH-M $(1,1)$ with the student-t distributional assumption and half-life measure. From the results, it was evident that volatility was persistent across all the stocks since the summation of ARCH and GARCH coefficients were all very close to one (1). The persistence and half-life measure revealed that, all the stocks exhibited some level of persistence in them and strong mean reversion. Fan Milk Limited was highly persistent with a weak mean reversion and a half-life of 19 days as compared to CAL Bank Limited, Produce Buying Company, Enterprise Group Limited, Uniliver Ghana Limited, Tullow Oil Plc and Benso Oil Palm Plantation which had 5 days, 7 days, 4 days, 5 days and 4 days respectively. Also all the returns series 
exhibited positive leverage effect parameter indicating that bad news influenced volatility than good news of the same magnitude and hence making volatility asymmetric.

\section{References}

[1] Ahmed, E. and Suliman, Z. (2011). Stock market volatility using garch models: Evidence from sudan. International Journal of Business and Social Science, 2(23):114-128.

[2] Banerjee, A. and Sarkar, S. (2006). Modelling daily volatility of the indian stock market using intra-day data. IIM CALCUTTA, Working paper.

[3] Bollerslev, T. (1986). Generalized autoregressive conditional heteroskedasticity, north holland. Journal of Econometrics, 31(3):307-327.

[4] Cater, R., Hill, E., and William, C. (2007). Principles of Econometrics, 3rd Edition New York. John Wiley and Sons, Inc.

[5] Cheong, C. (2009). Modelling and forecasting crude oil markets using arch-type models. Energy Policy, 37(6):23462355 .

[6] Chinzara, Z. and Aziakpono, M. (2009). Dynamic rreturn linkages and volatility transmission between south aafrica and world major stock markets. Studies in Economics and Econometrics, 33(3):69-94.

[7] Durbin, J. and Watson, G. (1950). Testing for serial correlation in least square regression. Econometrica, 37:409-428.

[8] Engle, R. (1982). Autoregressive conditional heteroskedasticity with estimates of the variance of the united kingdom inflation. Econometrica, 50:987-1007.

[9] Engle, R., Lilien, D., and Robins, R. (1987). Estimating time varying risk premia in the term structure, the arch-m model. Econometrica, 55(2):391-407.

[10] Engle, R. and Ng, V. (1993). Measuring and testing the impact of news on volatility. Journal of Finance, 48:1749-1778.

[11] Engle, R. and Patton, A. (2001). What good is a volatility model? Quantitative Finance, 1(2):237-245.

[12] Eview, M. (2007). Help system.

[13] Glosten, L., Jagannathan, R., and Runkle, D. (1993). On the relation between expected value and the volatility of the nominal excess return on stocks. Journal of Finance, 48:1779-1801.

[14] Hasan, M., Selin, A., and Fazle, R. (2013). Asymmetry and persistence of energy price volatility. International Journal of Finance and Accounting, 2(7):373-378.

[15] Jarque, C. and Bera, A. (1987). A test of nornormal of observations and regression residuals. International Statistical Review, 55:163-172.

[16] Kalu, E. and Friday A. S (2012). Modelling Asymmetry
Volatility in Nigerian Stock Exchange. Journal of Business and Management 4(12): 52-60.

[17] Kang, S., Kang, M., and Yoon, M. (2009). Forecasting oil price volatility. Energy Economics, 31(1):119-125.

[18] Kumar, D. and Maheswaran S. (2012). Modelling asymmetry and persistence under the impact of sudden changes in the volatility of the Indian stock market. IIMB Management Review, 24(3):123-136.

[19] Kwiatkowsky, D., Phillips, P., P., and Shin, Y. (1992). Testing the null hypothesis of stationarity against the alternative of a unit root. Journal of Econometrics, 54(13):159-178.

[20] Lee, J. and King, M. (1993). A locally most powerful based score test for arch and garch regression distrubances. Journal of Business and Economic Statistics, 7:259-279.

[21] Ljung, G. and Box, G. (1978). On the measure of lack of fit in time series models. Econometrica, 65(2):297-303.

[22] Magnus, F. and Fosu, O. (2006). Modelling and forecasting volatility of returns on the ghana stock exchange using garch models. American Journal of Applied Science, 3(10):20422048.

[23] Narayan, P. and Narayan, S. (2007). Modelling oil price volatility. Energy Policy, 35(12):6549-6553.

[24] Nelson, D. (1991). Conditional heteroskedasticity in asset returns: A new approach. Econometrica, 59(2):347-370.

[25] Ogega H. O and Freshia M. W (2016). Analysis of Asymmetric and Persistence in Stock Return Volatility in the Nairobi Security Exchange Market Phases. Journal of Finance and Economics, 4(3):63-73.

[26] Pindyck, R. (2004). Volatility in natural gas and oil markets. Journal of Energy and Development, 30(1):1-19.

[27] Poon and Granger (2003). Forecasting volatility in financial markets. Journal of Economic Literature, 41:2-478.

[28] Salisu, A. and Fasanya, I. (2013). Modelling oil price volatility with structural breaks. Energy Policy, 52(2):554 562 .

[29] Serletis, A. and Andreadis, I. (2004). Random fractal structures in north american energy markets. Energy Economics, 26(3):389-399.

[30] Tabak, B. and Cajueiro, D. (2007). Are markets oil markets becoming weakly efficient over time? a test for time-varying long-rang dependence in price and volatility. Energy Economics, 29(1):28-36.

[31] Takaendesa, P., Tsheole, P., and Aziakpono, M. (2006). Real exchange rate volatility and its effect on trade flows. new evidence from south africa. Studies in Economics and Econometrics, 30(3):79-97.

[32] Zakoian, J. (1994). Threshold heteroscedastic models. Journal of Economics Dynamics and Control, 18:931-944. 